\title{
FRACTURE-SEPARATION OF THE PROXIMAL EPIPHYSIS OF THE HUMERUS
}

\author{
J. F. Bourdillon, Cambridge, England
}

Fracture-separation of the proximal epiphysis of the humerus is an unusual injury of childhood and adolescence which may occur also as a birth injury. As with other epiphysial fracture-separations a fragment of diaphysis remains attached to the epiphysis and the stability after reduction depends largely upon the size of the attached diaphysial fragment. When this is small the reduced position is relatively stable; but when the fragment is large the displacement is both difficult to reduce and unstable after reduction. In this paper a method of reduction and fixation is presented. It is illustrated by four case reports and, for comparison, a fifth case is reported in which reduction was not undertaken. In all five cases there was a large diaphysial fragment.

Review of literature-Eighteen examples of this injury have been described by Roche (1926), Divis (1927), Zanoli (1928) and Aitken (1936). In ten of these patients the age was recorded as varying from thirteen to nineteen years, and this was the range of age of all five patients in the series now reported. Few details are given of the methods of treatment. Divis described one patient in whom reduction of the fracture was stable after manipulation; the radiographs showed a small attached diaphysial fragment. Aitken reported eleven cases: in two, after repeated unsuccessful manipulations, open reduction and internal fixation was performed; in no case was there permanent deformity; bowing persisted "for the first few months only "; there was shortening in seven cases, varying from one-quarter of an inch to one and a quarter inches. Zanoli in reporting 1,110 fractures of the upper limbs found five fracture-separations among a total of 162 fractures of the proximal end of the humerus which included thirty-five fractures in patients under the age of twenty years.

Mechanics of the injury-No discussion of the mechanism of the injury has been found in previous papers but from three patients in this series a clear history was gained. All three fell backwards on to the hand with the elbow extended and the arm behind the coronal plane, thus suggesting that strain on the proximal end of the humerus included compression, hyperextension and lateral rotation. It was reasonable to suppose, therefore, that reduction might be achieved by traction, flexion and medial rotation. This was tried and it proved successful, though it must be emphasized that considerable force was often needed. It was also found that if flexion and medial rotation were maintained, reduction remained stable after the traction was released. The limb was therefore immobilised in a plaster spica with the shoulder in a position of flexion and medial rotation.

\section{CASE REPORTS}

Case 1. Schoolboy, aged 15 years - Initial displacement severe-30 degrees angulation in the anteroposterior radiograph and 18 degrees in the lateral radiograph. Reduced on the day of injury; immobilised in a plaster spica for six and a half weeks. After removal of the plaster the limb could be lowered to within 30 degrees of the side and was supported in a sling with a large axillary pad of wool. Four weeks later there was slight limitation of adduction and medial rotation; other movements were full. Twenty months after injury there was no limitation of movement, no shortening and no disability. The radiographic appearances were indistinguishable from normal.

Case 2. Male, aged 18 years-Displacement moderate-12 degrees angulation in the antero-posterior radiograph and 23 degrees in the lateral radiograph. Reduced and immobilised on the day of injury. The patient was then transferred to another hospital where the plaster was removed after fourteen days and the arm " pulled down " across the chest; this was described as being very painful. Later radiographs showed recurrence of the original displacement. Four months after injury there was still pain at the extremes of movement. At six months the range of movement was full but there was a quarter-inch of shortening and radiographs showed union with some angulation and distortion of the humerus. 
Case 3. Schoolboy, aged 13 years-Displacement moderate-30 degrees angulation in the anteroposterior radiograph. Reduced on the day of injury and immobilised in plaster for six and a half weeks. Two weeks after removal of plaster there was slight limitation of medial rotation. Other movements were full and painless. Three months after injury the radiographs showed union in perfect alignment with minimal thickening and no shortening. At six months there was a full range of movement, no shortening and no disability. Radiographs showed slight irregularity of the diaphysis but the epiphysial line remained unfused.

Case 4. Schoolboy, aged 16 years-I Displacement severe-60 degrees of angulation in the lateral radiograph (Fig. 1). Reduced on the day of injury and immobilised in a plaster spica for thirty days. After removal of the plaster the limb was supported on an abduction splint. After four days the patient removed the splint; he found he could get the limb to his side in comfort. Five weeks after injury radiographs showed union in perfect alignment (Fig. 2). Eight weeks after injury there was no limitation of movement, no shortening and no pain. Power was almost normal.

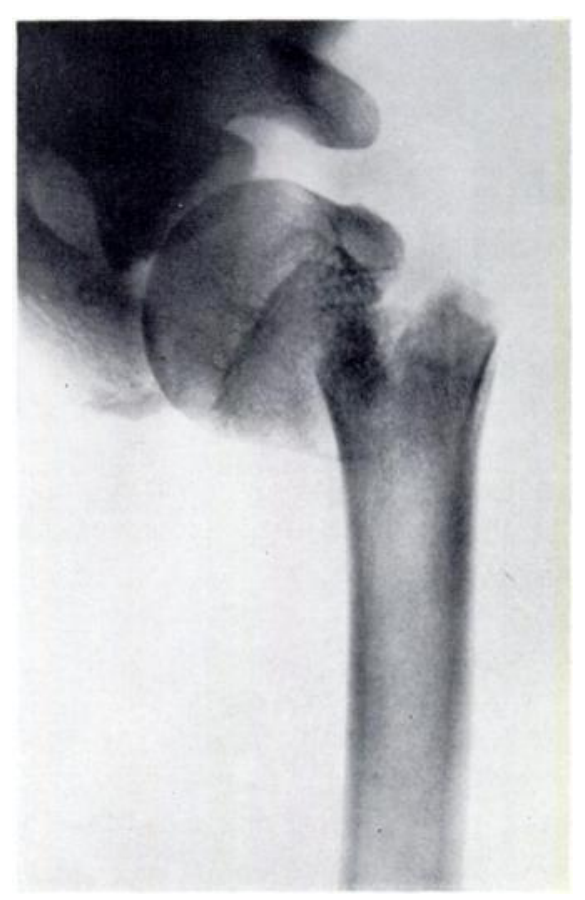

FIG. 1

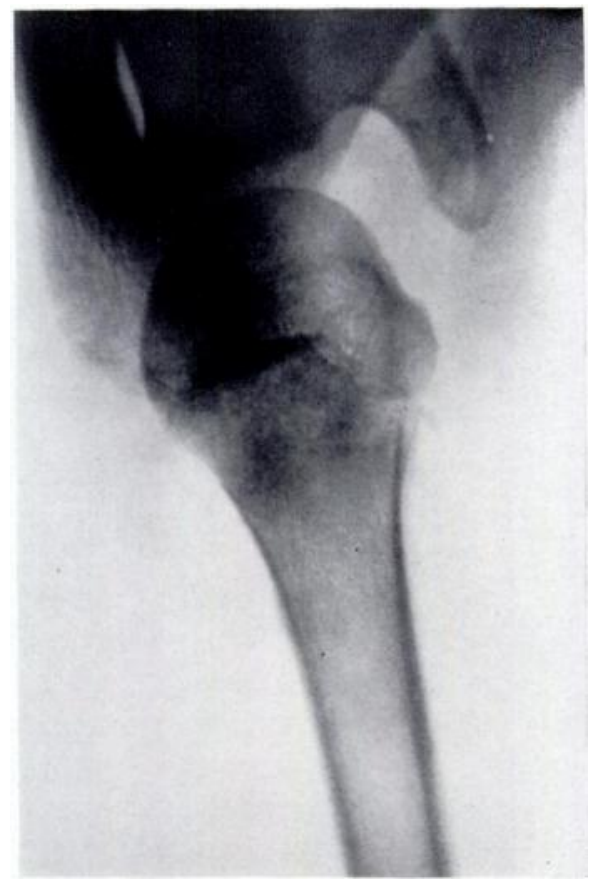

FIG. 2

Case 4. Fracture-separation of the upper humeral epiphysis with displacement and angulation (Fig. 1). Reduction was achieved by traction on the limb in the position of flexion and medial rotation. Radiography five weeks later show that the reduction has been maintained (Fig. 2).

Case 5. Female, aged 13 years-Displacement apparently slight. Only an antero-posterior radiograph was taken and this showed angulation of 10 degrees. Reduction was not attempted. The limb was supported in a sling and active movements were encouraged. Two years after injury there was a full range of movement and no symptoms other than occasional aching. Radiographs showed persistent angulation of the humerus -15 degrees in the antero-posterior view, 30 degrees in the lateral view. The apex of the angle was one and three-quarter inches from the epiphysial line. The epiphysis was still incompletely fused to the shaft. This case illustrates the necessity for radiographs in two planes at right angles. The original assessment of angulation as 10 degrees, based on the antero-posterior projection alone, was misleading.

Technique of reduction-The patient is anaesthetised and placed on his back. An assistant holds the shoulders level and presses upwards on the head of the humerus to prevent dislocation of the shoulder joint. The operator applies traction to the limb and brings it into 
a position of medial rotation and forward flexion; with the elbow at a right angle, the hand is then above and in front of the eye of the opposite side with the thumb pointing directly downwards (Fig. 3). It is usually necessary to press hard on the proximal end of the distal fragment. Once achieved, reduction is stable if the position of nearly full flexion and medial rotation is maintained. Radiographic confirmation of reduction before application of the plaster spica is advisable because it is difficult to determine clinically whether or not complete reduction has been gained. The plaster must fit snugly over the shoulder and the acromion and clavicle should be protected by a felt pad.

Discussion-Fracture-separation of the proximal epiphysis of the humerus often causes little disability even if the displacement is not reduced, but there may be shortening of the limb, sometimes exceeding one inch, due to angulation of the fragments or premature fusion of the epiphysis. Aitken (1936) described shortening in seven of eleven cases and in this series there was slight shortening in two cases. Such shortening may be avoided by correcting the angulation without increasing the epiphysial injury. This can be achieved by traction on the limb in the position of medial rotation and forward flexion, and if there is gross angulation and displacement such manipulation is advisable. The suggestion of Aitken that uncorrected bowing is corrected "after a few months" has not been borne out in this series. In one case the bowing was still obvious after two years.

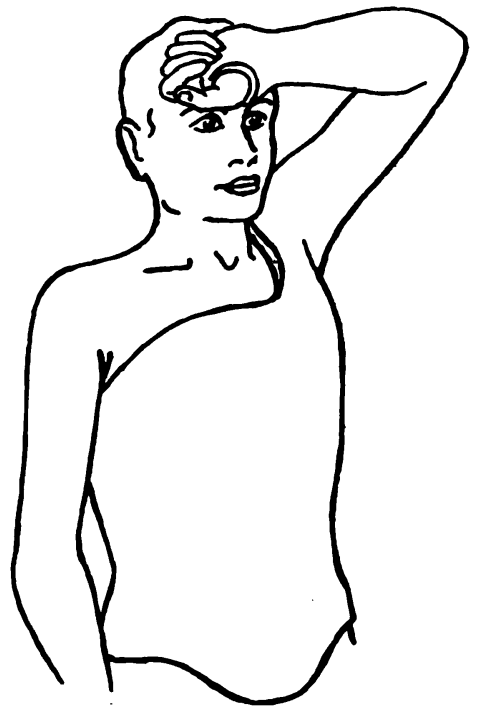

FIG. 3

After reduction the limb is immobilised in a position of flexion and medial rotation.

\section{SUMMARY}

Five cases of fracture-separation of the proximal epiphysis of the humerus are recorded. A method of reduction and immobilisation is described, and the literature is reviewed.

I wish to express my thanks to Mr R. Weeden Butler for much helpful advice and criticism.

\section{REFERENCES}

Aitken, A. P. (1936): End Results of Fractures of the Proximal Humeral Epiphysis. Journal of Bone and Joint Surgery, 18, 1036.

Divis, G. (1927): Epiphyseolysis humeri unter beträchtlicher Dislokation des Gelenkskopfes: Unblutige Reposition. Archiv für Orthopädische und Unfall-Chirurgie, 25, 342.

Roche, A. E. (1926): The Ultimate Result of a Case of Separated Upper Epiphysis of the Humerus. Clinical Journal, 55, 478.

Zanoli, R. (1928): Fratture dell'Epifisi Superiore dell'Omero. Chirurgia degli Organi de Movimento $12,445$. 